\title{
ALK Fusion Positive
}

National Cancer Institute

\section{Source}

National Cancer Institute. ALK Fusion Positive. NCI Thesaurus. Code C142135.

An indication that ALK fusion expression has been detected in a sample. 